\title{
POLÍTICA DE ASSISTÊNCIA SOCIAL E POVOS INDÍGENAS: LIMITES E POSSIBILIDADES PARA TRABALHO SOCIAL COM FAMÍLIAS
}

\author{
Valdênia Lourenço de Sousa ${ }^{1}$ \\ Frederico Jorge Ferreira Costa ${ }^{2}$
}

\begin{abstract}
Resumo:
O objetivo deste artigo é apresentar a lacuna existente entre as diretivas legais e a efetivação equitativa da assistência social direcionada aos indígenas. Sabemos que estes povos apresentam em sua cultura, diversas formas de vivências, organizações e manifestações tradicionais, sendo crucial a realização de políticas públicas condizentes aos seus anseios e necessidades. Nossas análises se debruçaram sobre os/as indígenas do Nordeste, especificamente aos/as pertencentes à etnia Pitaguary, localizados em Maracanaú-CE. Subsidiamos este estudo por meio de pesquisas bibliográficas, documentais e de campo; bem como pela análise das entrevistas realizadas com profissionais do serviço de Proteção e Atendimento Integral à Família (PAIF) do Centro de Referência de Assistência Social (CRAS) Pitaguary; e com lideranças e usuários indígenas pertencentes à referida etnia. Neste artigo, identificamos, ainda, que o trabalho social com as famílias se apresenta como peça importante na materialização da assistência social, cabendo a ela agir equitativamente nos espaços em que é demandada. Porém, o cenário contemporâneo vem intensificando o desmonte das políticas sociais, estando a política de assistência social no olho do furacão, distanciando-a cada vez mais da sua realização plena e equitativa.
\end{abstract}

Palavras-chaves: Assistência Social. Povos Indígenas. Trabalho Social com Famílias. Equidade.

\section{SOCIAL ASSISTANCE POLICY AND INDIGENOUS PEOPLE: THREATS TO THE PRINCIPLE OF EQUITY IN THE CONTEMPORARY CONTEXT}

\begin{abstract}
:
The aim of this article is to present the gap between legal directives and the equitable realization of social assistance directed to indigenous people. We know that these people present in their culture, different forms of experiences, organizations and traditional manifestations, being crucial to the realization of public policies consistent with their desires and needs. Our analyses were based on the indigenous peoples of the Northeast, specifically those belonging to the Pitaguary ethnicity, located in Maracanaú-CE. We support this study through bibliographical, documentary and field research; as well as the analysis of the interviews conducted with professionals of the Service of Protection and Integral Care to the Family (SPICF) of the Referral Center for Social Assistance (RCSA) Pitaguary; and with indigenous leaders and users belonging to the said ethnicity. In this article, we also identify that social work with families presents itself as an important part in the materialization of social assistance, and it is fitting to act equally in the spaces in which it is demanded. However, the contemporary scenario has intensified the dismount of social policies, being the policy of social assistance in the eye of the hurricane, disting it more and more from its full and equitable realization.
\end{abstract}

1 Assistente Social e Mestra em Serviço Social pela Universidade Estadual do Ceará - UECE. Técnica de referência no Centro de Referência de Assistência Social - CRAS Jereissati do Município de Maracanaú -CE. Membro do Observatório de Práticas de Assistência Social em Maracanaú - ObservaSUAS. E-mail: valdeniass1985@gmail.com

2 Doutor em Educação. Professor da Faculdade de Educação de Itapipoca da Universidade Estadual do Ceará (FACEDI/UECE). Pesquisador colaborador do Instituto de Estudos e Pesquisas do Movimento Operário (IMO). Membro do Programa de Pós-graduação em Educação (PPGE/UECE) e do Mestrado Acadêmico em Serviço Social, Trabalho e Questão Social (MASS/UECE). Coordenador do Grupo de Pesquisas Ontologia do Ser Social, História, Educação e Emancipação Humana (GPOSSHE). E-mail: frederico.costa@ uece.br 
Keywords: Social Assistance. Indigenous people. Social Work with Families. Equity.

\section{INTRODUÇÃO}

A assistência social brasileira se configura como uma política recente, prevista desde a constituição de 1988, mas que só passou a ser regulamentada no ano de 1993, com a Lei Orgânica da Assistência Social (LOAS). Sua organização e gestão foram discutidas a partir da Política Nacional de Assistência Social (PNAS), em 2004, e da Norma de Operação Básica do Sistema Único de Assistência Social (NOB/SUAS), em $2005^{3}$.

Com base na Constituição brasileira, a assistência social se refere a uma política pública, de caráter não contributivo, que, sob a primazia do Estado, visa garantir "mínimos sociais" a quem dela necessitar. Destina-se a vários segmentos sociais, no qual os povos indígenas são mencionados na PNAS (2004, p. 24) como um dos "segmentos sujeitos aos maiores graus de riscos sociais", devendo, assim, ter acesso a serviços, programas e projetos que atendam equitativamente suas demandas.

Desse modo, a PNAS assume a necessidade da adoção de mecanismos que possibilite aos/às indígenas ações que garantam o direito à vivência de seus costumes, 229 crenças, tradicionalidade, bem como a promoção de um trabalho social equitativo. Em 2016, o Ministério do Desenvolvimento Social (MDS) lançou uma orientação técnica sobre o “Trabalho Social com Famílias Indígenas” que, com algumas ressalvas ${ }^{4}$, descreve nuanças que possibilitam o norteamento para uma atuação diferenciada junto a estes povos.

Observamos que o atendimento aos povos indígenas, no âmbito da assistência social, foi problematizado recentemente. Tal política é permeada de contradições, que, consubstanciadas na matriz do favor e da caridade, acrescido ao contexto contemporâneo de desmonte das políticas sociais, torna-se um desafio cotidiano efetivá-la como direito social.

Direcionar nossas análises e percepções sobre a questão indígena significa nos reportar a um segmento que possui peculiaridades e especificidades diversas. Público esse com história social permeada por dizimação, lutas, resistências e negação de direitos, o que apresenta a necessidade de valorização e visibilidade para questões que foram negligenciadas durante muito tempo pelos serviços públicos e instituições de fomento.

A referida normativa foi revisada e aprovada pela Resolução CNAS n³3/2012.

4 Embora seja interpretado como um avanço, no que tange ao trabalho social com o público indígena, as definições e configurações dos modos de vida descritos nesse documento deixa a desejar no que concerne a diversidade indígena no Brasil contemporâneo, existindo uma lacuna na interpretação e percepção dos/as índios/as do Nordeste, direcionando seu olhar para os indígenas da região Norte.

\begin{tabular}{|l|c|c|c|c|}
\hline Revista Dialectus & Ano 5 & n.13 & Agosto - Dezembro 2018 & p. $228-244$ \\
\hline
\end{tabular}




\section{POLÍTICA DE ASSISTÊNCIA SOCIAL E POVOS INDÍGENAS...}

Valdênia Lourenço de Sousa / Frederico Jorge Ferreira Costa

Portanto, este estudo ${ }^{5}$ foi subsidiado por pesquisas bibliográficas, documentais e de campo; bem como pela análise das entrevistas realizadas com profissionais do serviço de Proteção e Atendimento Integral à Família (PAIF) do Centro de Referência de Assistência Social (CRAS) Pitaguary; e com lideranças e usuários indígenas pertencentes à referida etnia, situados em Maracanaú-CE, região metropolitana de Fortaleza.

Os/as indígenas vivenciaram um longo processo de supressão de direitos sociais e culturais, tencionados desde o período constitutivo do Estado Brasileiro, tendo inúmeros rebatimentos na contemporaneidade. Os tópicos a seguir disporão sobre o contexto social, econômico e cultural indígena, inserindo-os como público de políticas públicas.

\section{1 ÍNDIOS NO BRASIL: ASPECTOS HISTÓRICOS, ECONÔMICOS E SOCIOCULTURAIS}

No Brasil, os povos indígenas possuem uma formação cultural, social e econômica diretamente vinculada às refrações de uma questão social latente, no qual, foram expostos a processos de "extermínio", genocídio e/ou o etnocídio presentes desde o período colonial.

Constatamos nos escritos de Espinosa (2007) o quão os processos de etnocídio foram danosos a esses povos, configurando-se num movimento de negação e expropriação do ser índio, subalternizando-os e desqualificando-os enquanto sujeitos passíveis de autenticidade humana, trazendo marcas profundas aos seus descendentes. Foi com base no discurso hierarquizante que inúmeras etnias foram dizimadas e perseguidas. Desse modo, consubstanciadas na racialização e segmentação humana escalonada, essas práticas etnocídas foram se instituindo e legitimando.

Marx (2013) em "O Capital" apresentou que o processo de expropriação transformou homens do campo em vendedores de si mesmos e que "a história dessa expropriação está gravada nos anais da humanidade com traços de sangue e fogo" (MARX, 2013, p. 787). Ao fazer essa analogia com a realidade brasileira, constatamos que a

5 Este estudo revela parte dos resultados da dissertação intitulada: "POLÍTICA DE ASSISTÊNCIA SOCIAL E POVOS INDÍGENAS: UM ESTUDO SOBRE O TRABALHO SOCIAL COM FAMÍLIAS REALIZADO NOS CRAS INDÍGENAS QUE ATENDEM AS ETNIAS PITAGUARY E JENIPAPO-KANINDÉ NA REGIÃO METROPOLITANA DE FORTALEZA-CE", submetido ao comitê de ética da Universidade Estadual do Ceará (UECE) e aprovado com o parecer de $\mathrm{n}^{\circ}$ 1.695.052, passando também pelo crivo ético da Comissão Nacional de Ética em Pesquisa, aprovado com o parecer de nº 1.768.838.

\begin{tabular}{|l|l|l|l|l|}
\hline Q Povista Dialectus & Ano 5 & n.13 & Agosto - Dezembro 2018 & p. $228-244$ \\
\hline
\end{tabular}


expropriação de lá, tem fundamentos semelhantes com os de cá. A usurpação das terras coletivas e uma série de horrores e opressão foi parte constitutiva da pré-história do modo de produção capitalista no Brasil, no qual os/as indígenas foram os/as primeiros/as a vivenciarem as refrações da questão social, ainda que latente (SILVA, 2008).

Vários foram os artifícios de dominação em que os povos indígenas eram tidos como primitivos e atrasados, fazendo-se necessário reelaborá-los, domesticá-los, provocando espistemicídios. Toda forma de viver diferenciada foi violentamente combatida, racializada, modificada e "homogeneizada", seja por meio da catequese, do aldeamento, da negação das linguagens específicas, da escravização e da domesticação.

Ressaltamos aqui que os processos de genocídio e etnocídio estão intimamente vinculados aos mecanismos de expropriação pela qual passaram (e ainda passam) os povos indígenas. Referem-se ao processo de extermínio e ao combate intensivo aos seus modos de vida. Segundo Espinosa (2007, p. 274),

El problema del genocidio está latente en la representación misma, y es dinamizado por unas experiencias históricas de alterización, jerarquización social y exclusión. El concepto de genocidio cultural (o etnocidio) no se refiere simplemente a asesinatos en masa, sino, sobre todo, al acto de eliminar la existencia de un pueblo y silenciar su interpretación del mundo.

Subsidiados em Pinheiro (2007), identificamos que um dos principais conflitos estabelecidos entre os europeus, igreja católica e os povos indígenas estava centrado nas disputas pelas terras e no etnocídio, a fim de transformá-los em produtores de mercadorias para que esses admitissem o modo de vida que se estabelecia no Brasil colonizado. As intervenções estatais foram se centrando historicamente numa perspectiva "integracionista", em que os indígenas foram silenciados e tolhidos no seu modo de ser.

Vale ressaltar que a Lei $\mathrm{n}^{\circ} 601$ de 1850 (Lei das Terras) teve rebatimento direto sobre as terras e as comunidades indígenas. Com base nessa lei seria "garantido" aos nativos o direito ao usufruto de uma parcela territorial, porém condicionava-a a uma comprovação de indianidade estereotipada e taxativa. Logo, este mesmo índio que foi interditado de vivenciar sua cultura deveria "retomá-la" para garantir o seu direito à terra.

Portanto, o mecanismo que deveria assegurar direito aos povos originários era na realidade algo negativo, pois emponderou discursos estereotificantes (CARNEIRO DA CUNHA, 2012). Tais ideários têm rebatimentos presentes na contemporaneidade, pois quando a sociedade envolvente desenvolveu/desenvolve padrões de indianidade, há uma retomada

\begin{tabular}{|c|c|c|c|c|}
\hline Qenista Dialeatus & Ano 5 & n.13 & Agosto - Dezembro 2018 & p. $228-244$ \\
\hline
\end{tabular}


violadora de objetivações desse "ser índio" que acabam por consubstanciar normativas e legislações que, por vezes, desacreditam, "definem” e/ou fantasiam esse público. Não esqueçamos que o Estado também é colonizador!

Com a constituição de 1988, resultado de um intenso processo de lutas e mobilização social, há uma diretiva para a construção de um sistema universal de proteção social. O texto constitucional imprime, ao menos na legalidade, o direito à diferença. Enquanto isso, no âmbito internacional, a Convenção no 169 da Organização Internacional do Trabalho (OIT), aprovada em 1989, reconhece direitos de ordem social e cultural aos povos indígenas. No Brasil, essa convenção foi promulgada tardiamente, por meio do Decreto 5.051, de 19 de abril de 2004, e, além do direito à tradicionalidade e vivências específicas, é previsto aos povos indígenas o direito à seguridade social.

Sob essa constituinte os/as indígenas tiveram "legalizados" seus direitos ao território, às vivencias culturais, religiosas, e políticas sociais diferenciadas. Foi a primeira constituição que concedeu o direito às diversidades sociais e culturais no Brasil. Vale ressaltar que a promoção das políticas de seguridade social de forma equitativa representa, ainda, um quadro de grande complexidade, aridez e desafio.

\section{1 Índios do Nordeste: (re) descobrindo as especificidades destes povos}

Historicamente, as ações estatais destinadas aos povos indígenas assumiram perspectivas "integracionistas" e "disciplinadoras". Contudo, as normativas internacionais exigiram/exigem do Brasil condutas mais democráticas e um novo olhar para este segmento, com vistas a garantir seus direitos sociais, étnicos, econômicos e culturais. Mas, vale mencionar que um mero direcionamento legal não tem sido capaz de desconstruir mais de 500 anos de estereótipos de indianidade.

Com base no Censo indígena de 2010, existem no Brasil 305 etnias, representando $0,4 \%$ da população nacional, contrastando ao informado pelo Instituto Socioambiental ${ }^{6}$ ao relatar a existência de apenas 254 povos indígenas. A discrepância das informações demonstra a permanência dos processos de extermínio desses povos, apontando ainda para a necessidade de atualização constante dessas estatísticas.

6 As informações fornecidas pelo site do Instituto Socioambiental Disponível em: $<$ https://pib.socioambiental.org/pt/c/quadro-geral >. Acesso em: 20 de dez. de 2017.

\begin{tabular}{|l|c|c|c|c|}
\hline Q Rovista Qialectus & Ano 5 & n.13 & Agosto - Dezembro 2018 & p. $228-244$ \\
\hline
\end{tabular}




\section{POLÍTICA DE ASSISTÊNCIA SOCIAL E POVOS INDÍGENAS...}

Valdênia Lourenço de Sousa / Frederico Jorge Ferreira Costa

Luciano (2006) aponta que desde os anos de 1990 vem ocorrendo no Brasil um processo intenso de "etnogênese" ou "reetinização". Pois, "os povos indígenas que por força de séculos de repressão colonial escondiam e negavam suas identidades étnicas, agora reivindicam o reconhecimento de suas etnicidades e de suas territorialidades nos marcos do Estado brasileiro" (Ibidem, p. 33). Atualmente, os/as índios/as, sobretudo na região Nordeste e no sul da região Norte, estão reafirmando e reformulando as suas culturas.

Bartolomé (2006), ao lançar estudos sobre a etnogênese na América Latina utiliza-se dos estudos de Porto Alegre (1998) para afirmar que houve no Nordeste brasileiro a construção ideológica do "desaparecimento" dos povos indígenas na região. O autor elucida que a "transfiguração cultural" que passaram as mais variadas etnias da região não significa o enfraquecimento das identidades étnicas, essas foram apenas reformuladas em decorrência das modificações societárias e imposições sociais. Afinal, índios/as que (re)vivem, resistem e lutam para se autoafirmarem estão, também, permeados por ideologias, sensos-comuns e autoimagens construídas e reconstruídas socialmente sobre esse ser índio/índia.

Os/as indígenas, em especial os/as do Nordeste brasileiro, eram identificados como caboclos e/ou moradores das zonas rurais, passando a afirmar sua pertença principalmente nas décadas de 1970 e 1980 . Tal processo representou um despertar étnico que só foi possível após um longo caminho de lutas e "retomada" do direito legal de ser índio, o qual foi/é visto pela sociedade envolvente com muito estranhamento. O processo de negação desses povos está entranhado numa sociedade que não concebe a eles a possibilidade de assimilarem e "desfrutarem" da modernidade. Assim, o ser índio estaria intimamente relacionado com uma cultura estanque.

Ao fazer um traçado analítico sobre os povos indígenas no Ceará identificamos que o estado é permeado por uma história de negação dos "nativos" em seu território, fato que podemos visualizar no decreto de $1861^{7}$, que afirmava não haver indígenas nessas terras. Essa situação destaca as investidas do poder público no ocultamento desses povos, em especial no que se refere à garantia de direitos, como: a legitimidade de suas terras e de suas práticas culturais.

Os povos indígenas encontram-se envoltos pelas refrações da questão social, apresentando demandas à política de assistência social, suscitando do Estado e dos serviços

7 Conforme trecho do Relatório apresentado à Assembleia Legislativa Provincial por José Bento da Cunha Figueiredo Júnior, em 09/10/1863: “Já não existem aqui índios aldeados ou bravios. [...] Ainda hoje se encontra maior número de descendentes das antigas raças; mas acham-se misturados na massa geral da população, composta na máxima parte de forasteiros, que os excedendo em número, riqueza e indústria, tem havido por usurpação ou compras as terras pertencentes aos aborígenes" (RATTS, 2009, p.17).

\begin{tabular}{|c|c|c|c|c|}
\hline Rovista Wialectus & Ano 5 & n.13 & Agosto - Dezembro 2018 & p. $228-244$ \\
\hline
\end{tabular}


públicos atividades que atendam a contento suas demandas e anseios. Sinalizamos que a assistência social, em nível de Proteção Social Básica (PSB), materializa-se não só pela via da transferência de renda, mas também por meio do Trabalho Social com as Famílias (TSF).

O serviço de Proteção e Atendimento Integral à Família (PAIF) representa uma das principais atividades desenvolvidas pelas equipes técnicas nas unidades de CRAS, promovendo ações de acolhida, oficinas, atendimentos, acompanhamentos, encaminhamentos, buscando atender a família em sua integralidade e acionando políticas setoriais, quando necessário.

A política de assistência social brasileira dispõe de 8.088 Centros de Referência de Assistência Social (CRAS) e 2.372 Centros de Referência Especializados de Assistência Social (CREAS), com um quantitativo de aproximadamente 290.156 trabalhadores/as. Nesse universo, 574 CRAS e 240 CREAS atendem demandas advindas dos povos indígenas, sendo que apenas 21 CRAS encontram-se localizados nesses territórios, havendo ainda 1.254 equipes volantes que lidam com esse público, revelando que o número de CRAS localizados em áreas indígenas é insuficiente para a demanda. Vale ressaltar que os CRAS localizados nestes territórios específicos, nem sempre atendem exclusivamente estes povos. (BRASIL, MDS, 2016).

Foi nesse contexto que analisamos a etnia Pitaguary e como a Proteção Social Básica da política de assistência social se materializa neste território etnicamente diferenciado. Para tal foi necessário (re) conhecer de perto a história desse povo, elucidando aspectos socioeconômicos, culturais e territoriais.

\section{REALIDADE INDÍGENA PITAGUARY E OS (DES)CAMINHOS PARA A PROMOÇÃO DE UMA ASSISTÊNCIA SOCIAL EQUITATIVA}

Os/as índios/as Pitaguary são descendentes dos Potiguaras e vivem próximo as áreas serranas, nos municípios de Maracanaú-CE e Pacatuba-CE. Esses povos iniciaram o processo de reconhecimento étnico e de busca por seus direitos em 1991, sendo reconhecido pela câmara municipal de Maracanaú no ano de 1993, ao "doar" 107 hectares de terras para os Pitaguarys, possibilitando o retorno de muitos indígenas que se encontravam dispersos no município.

Em 1997, o Grupo de Trabalho da Fundação Nacional do Índio (FUNAI) realizou estudos para identificação e delimitação territorial indígena, no qual "destinou" 1.735,60 hectares de terras para o povo Pitaguary. Vale ressaltar que este território é permeado por

\begin{tabular}{|c|c|c|c|c|}
\hline Qevista Dialectus & Ano 5 & n.13 & Agosto - Dezembro 2018 & p. $228-244$ \\
\hline
\end{tabular}


conflitos, presença de posseiros e empresas que se utilizam da contratação de indígenas para perpetuarem sua permanência no território.

A terra indígena Pitaguary encontra-se demarcada, mas ainda não foi homologada, sofrendo os rebatimentos da morosidade estatal para a provisão do usufruto irrestrito do território. Essa instabilidade fragiliza a etnia e a deixa exposta a situações de possíveis conflitos, como evidenciado no relato abaixo:

[...] a gente tá passando por uma questão de exploração da terra mesmo. Estão vindo muitas pessoas pra nossa terra, muitas pessoas pra dentro do território que nós desconhecemos, que nós não reconhecemos como nossos parentes. Que não estão dentro dos troncos familiares Pitaguary. (LIDERANÇA INDÍGENA, JUREMA).

Atualmente, os Pitaguarys correspondem a aproximadamente 4.313 habitantes, dos quais 3.274 localizam-se no município de Maracanaú (CDPDH, 2015). O território em questão tem como principais limites as aldeias do Santo Antônio, Horto Florestal e Olho D’água, no município de Maracanaú. E, em Pacatuba, faz fronteira com as localidades de Monguba e Pavuna (PINHEIRO, 2002).

As famílias indígenas Pitaguary sinalizam, por meio das suas vivências e costumes, particularidades que à primeira vista se confundem com as características de famílias não indígenas, porém, basta observá-los por um relativo tempo que é possível identificar especificidades próprias desta comunidade. O toré representa um rito muito importante para eles. Esta dança indígena é realizada principalmente em dias de festejos, tendo como principal o realizado no dia 12 de junho, momento em que se reúnem os povos de todas as aldeias (Horto, Olho D’água, Santo Antônio e Monguba), etnias próximas e visitantes para juntos dançarem o toré em torno da Mangueira bicentenária, localizado na aldeia mãe (Santo Antônio).

Em 2006, foi implantado no território Pitaguary um CRAS específico ${ }^{8}$, compondo os três primeiros CRAS $^{9}$ do município, que, com base no Plano Municipal da Assistência Social (2014),

Respeitando a diversidade e as especificidades étnicas, preconizadas pela PNAS, a criação de um CRAS INDÍGENA dentro da comunidade indígena, buscou assegurar o processo de inclusão social das famílias, através de um conjunto de ações socioassistenciais articuladas entre o poder público e a sociedade, potencializando os programas, projetos e serviços existentes e construindo novas estratégias, de forma a

8 Vale sinalizar que a criação de um equipamento destinado especificamente aos/às indígenas da região, revela uma tentativa de garantia de acesso a um atendimento socioassistencial diferenciado e equitativo para estes povos.

9 Atualmente, Maracanaú-CE possui 11 unidades de CRAS.

\begin{tabular}{|l|c|c|c|c|}
\hline Q & Anista \\
\hline
\end{tabular}


permitir às famílias indígenas a apropriação de meios e recursos necessários ao alcance de sua identidade étnica e autonomia. (MARACANAÚ, 2014, p. 60).

As atividades no CRAS Indígena iniciaram, primeiramente, na Casa de Apoio Pitaguary (local que hoje funciona a Casa Digital) e, em dezembro de 2009, foi reinaugurado em sede própria. A referida unidade é cofinanciada pelo Estado, construída numa estrutura física diferenciada, com modelo arquitetônico semelhante ao formato de "oca". O equipamento atende exclusivamente as famílias indígenas do município, realizando seus serviços, programas e projetos por intermédio do trabalho social com famílias, visando identificar mediações e estratégias para combaterem situações sociais e econômicas de exposição às refrações da questão social que acometem a etnia Pitaguary. Ocorre ainda a inserção das famílias em situação de pobreza e/ou extrema pobreza em programas de transferências de renda do Programa Bolsa Família.

Em novembro de 2016, a equipe do CRAS Indígena Pitaguary era composta por um coordenador, dois técnicos de nível superior (assistente social e psicólogo), um profissional responsável pelo Cadastro Único, um agente administrativo, um orientador social, um educador social, um profissional de serviços gerais e um porteiro. Vale ressaltar que os quatro últimos profissionais têm pertença étnica Pitaguary.

No que concerne ao vínculo profissional, quatro profissionais eram efetivos, dois regidos pela CLT e três em regime de contrato temporário. Para um município com nível de gestão plena, não houve a garantia de uma equipe mínima de referência do PAIF. Tal situação não ocorre apenas nesse CRAS, revelando o processo constante de sucateamento da assistência social. Afinal, segundo Raichelis (2010) o SUAS é também permeado por contextos de precarização, no qual:

[...] cresce o trabalho precário, parcial, temporário, bem como as diferentes modalidades de flexibilização dos vínculos e de direitos, além da ampliação do trabalho voluntário e das diversas formas de cooperativismo e empreendedorismo, que ocultam novos modos de gestão e (auto) exploração do trabalho. (RAICHELIS, 2010, p. 758).

Com base nos dados cedidos pelo setor da vigilância socioassistencial de Maracanaú-CE, subsidiado pelas informações contidas no Cadastro Único ${ }^{10}$ (CadÚnico) em

10 Elucidamos que as informações contidas no Cadastro Único são de cunho autodeclaratório e contemplam questões atinentes a situação econômica, habitabilidade, acesso a programas sociais, composição familiar, dentre outros.

\begin{tabular}{|l|l|l|l|l|}
\hline Q Rovista Dialectus & Ano 5 & n.13 & Agosto - Dezembro 2018 & p. $228-244$ \\
\hline
\end{tabular}


outubro de 2016, foi identificado a presença de 864 famílias indígenas cadastradas, totalizando 2.897 Pitaguarys, conforme tabela abaixo.

Tabela 1 - Lista de famílias e pessoas cadastradas no CadÚnico referenciadas no CRAS Indígena Pitaguary

\begin{tabular}{|l|r|r|}
\hline \multicolumn{1}{|c|}{ Localidade } & Familias cadastradas & \multicolumn{1}{c|}{ Pessoas cadastradas } \\
\hline Horto & 347 & 1138 \\
\hline Olho D'agua & 284 & 962 \\
\hline Santo Antônio & 233 & 797 \\
\hline TOTAL & $\mathbf{8 6 4}$ & $\mathbf{2 8 9 7}$ \\
\hline
\end{tabular}

FONTE: MARACANAÚ (Ceará). Secretaria de Assistência Social e Cidadania. Perfil das Famílias do Cadastro Único CRAS INDÍGENA. Maracanaú, CE: SASC, 2016.

O CRAS em estudo é considerado um dos poucos do estado que se destinam exclusivamente para o atendimento à demanda indígena. Ao nos direcionarmos para o perfil de inserção de famílias no Cadastro Único, identificamos que dos 3.274 Pitaguarys residentes em Maracanaú-CE, 2.897 (88,48\%) são referenciados por esta unidade de CRAS, ou seja, possuem renda familiar que não ultrapassam três salários mínimos ou meio salário mínimo per capita.

No que concernem às informações referentes à renda declarada para o Cadastro Único, percebemos que muitas famílias estão em situação considerada de pobreza ou extrema pobreza $^{11}$, elencando-os como público demandatário de políticas de transferência de renda do Programa Bolsa Família e de Trabalhos Sociais. A tabela a seguir evidencia essa realidade:

Tabela 2 - Renda per capita declarada pelas famílias indígenas Pitaguary

\begin{tabular}{|l|r|r|r|r|r|}
\hline \multicolumn{7}{|c|}{ Distribuição por renta per capita } \\
\hline Localidade & $\mathbf{0 , 0 0 - 8 5 , 0 0}$ & $\mathbf{8 5 , 0 1 - 1 7 0 , 0 0}$ & $\begin{array}{c}170,01- \\
440,00\end{array}$ & $\begin{array}{c}\text { 440,01- } \\
\mathbf{8 8 0 , 0 0}\end{array}$ & $\begin{array}{c}\text { Acima de } \\
\mathbf{8 8 0}\end{array}$ \\
\hline Horto & 150 & 67 & 94 & 34 & 2 \\
\hline Olho D'agua & 102 & 54 & 93 & 35 & 0 \\
\hline Santo Antônio & 98 & 35 & 64 & 32 & 4 \\
\hline TOTAL & $\mathbf{3 5 0}$ & 156 & $\mathbf{2 5 1}$ & $\mathbf{1 0 1}$ & $\mathbf{6}$ \\
\hline
\end{tabular}

FONTE: MARACANAÚ (Ceará). Secretaria de Assistência Social e Cidadania. Perfil das Famílias do Cadastro Único CRAS INDÍGENA. Maracanaú, CE: SASC, 2016.

11 Conforme perfil para inclusão nos programa de transferência de renda do PBF, as famílias que possuem renda per capita declarada de até $\mathrm{R} \$ 85,00$, encontram-se em situação de extrema pobreza, já as famílias que apresentam renda per capita de R \$85,01 ate R\$170,00 são identificadas como em situação de pobreza.

\begin{tabular}{|c|c|c|c|}
\hline Revista Aidlectus & Ano 5 & n.13 & Agosto - Dezembro 2018 \\
\hline
\end{tabular}


Observamos que, do total de famílias cadastradas, 350 famílias (40,50\%) encontram-se expostos à situação de extrema pobreza e $156(18,05 \%)$ estão em situação de reconhecida pobreza, ficando assim, suscetíveis as mais variadas formas de cerceamento de direitos e privações. Tal situação acomete mais de um terço dos/as índios/as Pitaguary, ratificando a necessidade de atuação de políticas sociais e econômicas, no sentido de garantir a esses povos o acesso a direitos sociais e renda para o custeio das suas necessidades básicas. Muitas famílias indígenas foram, em decorrência das informações declaradas, inseridas em programas de transferências de renda como disposto a seguir:

Tabela 3 - Quantitativo das famílias beneficiadas por bairro

\begin{tabular}{|l|r|rr|}
\hline \multicolumn{1}{|c|}{ Localidade } & Famílias beneficiárias PBF & \multicolumn{1}{c|}{ Valor dos beneficios } \\
\hline Horto & 189 & R\$ & $35.378,00$ \\
\hline Olho D'agua & 151 & R\$ & $28.071,00$ \\
\hline Santo Antônio & 127 & R\$ & $25.505,00$ \\
\hline TOTAL & $\mathbf{4 6 7}$ & $\mathbf{R} \$$ & $\mathbf{8 8 . 9 5 4 , 0 0}$ \\
\hline
\end{tabular}

FONTE: MARACANAÚ (Ceará). Secretaria de Assistência Social e Cidadania. Perfil das Famílias do Cadastro Único CRAS INDÍGENA. Maracanaú, CE: SASC, 2016.

Sabemos que a pobreza não se limita a questões financeiras e, em comunidades indígenas, há questões que evidenciam outras demandas de pauperização, como situações advindas do período de estiagem, poluição dos rios e lagoas, a presença de posseiros ou mesmo os conflitos locais. Porém, devemos mencionar que em decorrência desses indígenas estarem próximos da sociedade envolvente, suas vivências e sociabilidades estão circundados também pela ordem do capital e no apelo ao consumo. No tocante a renda per capita, temos as seguintes informações:

Tabela 4 - Informações acerca da composição familiar e renda per capita das famílias indígenas Pitaguary inseridas no Cadúnico

\begin{tabular}{|l|rr|rr|}
\hline \multicolumn{1}{|c|}{ Localidade } & \multicolumn{2}{c|}{ Renda per capita } & \multicolumn{2}{c|}{$\begin{array}{c}\text { Media de composição } \\
\text { familiar }\end{array}$} \\
\hline Horto & \multicolumn{2}{|c|}{ R\$ } & 183,77 & 3,28 \\
\hline Olho D'agua & R\$ & 212,27 & 3,39 \\
\hline Santo Antônio & R\$ & 216,24 & 3,42 \\
\hline
\end{tabular}

FONTE: MARACANAÚ (Ceará). Secretaria de Assistência Social e Cidadania. Perfil das Famílias do Cadastro Único CRAS INDÍGENA. Maracanaú, CE: SASC, 2016.

\begin{tabular}{|l|c|c|c|c|}
\hline Q & Anista \\
\hline
\end{tabular}


Notamos que a renda per capita declarada, não ultrapassa R \$250,00 e, pela composição familiar, percebemos que a maioria dessas famílias sequer conseguem ter acesso a um salário mínimo mensal. A existência de uma unidade de CRAS no território indígena possibilita aos/às usuários/as o acesso aos serviços e benefícios socioassistenciais, proporcionados pelas ações do Trabalho Social, exigindo-se atividades mais próximas da realidade destes usuários.

Vimos que a composição de uma equipe mínima para o $\mathrm{PAIF}^{12}$ não foi garantida, logo, a indicação de um profissional antropólogo, como proposto pelas normativas e orientações técnicas, torna-se algo surreal. As fragilidades de vínculos trabalhistas e a não garantia da equipe mínima de referência incide diretamente nas práxis sociais destes trabalhadores e no total desrespeito ao preconizado pela NOB-RH/SUAS que orienta, ainda, sobre a necessidade de servidores efetivos.

As demandas que chegam ao PAIF são diversas e tem relação estreita com situações macroestruturais, com rebatimentos diretos nas relações sociais, individuais e/ou familiares. Indagamos os/as profissionais sobre as principais demandas apresentadas pelo público indígena, nos sendo relatado que,

\begin{abstract}
A gente vê muito a questão de conflitos familiares, dificuldade na condução da educação dos filhos, a questão do desemprego, o próprio alcoolismo que acaba interferindo também nas relações familiares. E aí o que a gente traça como equipe profissional é o fortalecimento dessa família, com esse empoderamento a essa família, e dizendo o quê que é o CRAS, no que é que nós podemos estar auxiliando, apontando como algumas estratégias. É um trabalho assim meio delicado porque às vezes eles querem condicionar essa situação à nossa atuação, como se nós fossemos resolver. Mas aí é um trabalho assim de costura mesmo que a gente vai tentando dentro daquela dinâmica familiar vendo o quê que a gente tem a oferecer. (PROFISSIONAL 4).
\end{abstract}

São várias as expressões da questão social que se apresentam como demanda e embora representem situações, por vezes, semelhantes aos demais CRAS, não se pode perder da análise que estes sujeitos e famílias possuem pertenças étnicas diferenciadas, emanando a

12 No município investigado, por possuir característica de gestão plena, devem ser adotados quatro profissionais para compor o PAIF, no qual o mesmo designa dois assistentes sociais, um psicólogo e um pedagogo. Porém, no ato da pesquisa identificamos que havia apenas um assistente social e um psicólogo compondo a equipe do PAIF, e um coordenador. Vale acrescentar que para as ações desenvolvidas com famílias com especificidades étnicas, é recomendada a contratação de antropólogos, profissional não identificado em nenhum dos CRAS pesquisados. Por este trabalho se constituir num recorte do trabalho dissertativo da autora, a pesquisa de origem analisou a realidade social das atividades sociais em dois CRAS, um que atende a etnia Pitaguary e outra que atende a etnia Jenipapo Kanindé.

\begin{tabular}{|l|c|c|c|c|}
\hline Revista Dialectus & Ano 5 & n.13 & Agosto-Dezembro 2018 & p. $228-244$ \\
\hline
\end{tabular}


necessidade de perceber: sobre qual família estamos falando? Quais as normas de convívio entre estes pares? O que há de deliberação e organização nas aldeias? Quais os impactos do contato constante com a sociedade envolvente? São várias perguntas que precisam ser compreendidas e externalizadas em práxis sociais que já não se fazem semelhantes, pois depende do território, constituído de sujeitos com demandas sociais diversas, necessitando de uma intervenção equitativa. Deve-se ater também para o cuidado ao lidar com as situações sociais apresentadas, a fim de não ir de encontro às especificidades da comunidade, visando não reproduzirem ações violadoras e disciplinadoras. É fundamental que os/as trabalhadores descolonizem o olhar e o exercício profissional, percebendo quais as reais necessidades dos usuários/as, como expresso no relato abaixo:

Então assim, precisa de muita sutilidade para perceber o que mais eles querem e não o que a gente pensa que deve ou não ser. (PROFISSIONAL 4).

A cultura indígena foi sinalizada como uma bússola para a realização e compreensão das atividades laborais nesses territórios. Porém, há uma falsa ideação de que estes/as trabalhadores/as imprimiriam nas suas ações o modo de ser indígena, quando na realidade estes/as jamais poderão promover uma cultura que não é sua, no máximo poderão auxiliar na promoção de direitos, com uma atuação que respeite, compreenda e coadune com as demandas que lhes são apresentadas. Pois, quem promove, realiza e vivencia a cultura são os/as indígenas e não os/as profissionais.

Identificamos algumas especificidades no funcionamento deste equipamento, pois, quando ocorrem óbitos de pessoas representativas para a aldeia, ou mesmo "movimentos sociais" promovidos pela etnia, não há atendimento na unidade e, neste último, ocorre a participação dos/as profissionais nos espaços de luta e resistência indígena.

As práxis sociais desenvolvidas por esses/as trabalhadores/as se dão, principalmente, mediadas pelo atendimento, acompanhamento familiar, grupos (gestantes ou mesmo nos Serviços de Convivência e Fortalecimento de Vínculos) e visitas domiciliares. Tais métodos são utilizados para que a equipe e/ou o/a profissional possa melhor compreender as questões que acometem as famílias e, juntos, realizar planos de acompanhamento familiar, encaminhamentos, prover benefícios, direcionar para políticas socioassistenciais e/ou setoriais. Segundo os/as profissionais, o acompanhamento familiar se desenvolve majoritariamente de forma individual, pois os vínculos familiares (graus de parentesco) existentes na aldeia dificultam a escuta de situações vivenciadas pelas famílias, já que na

\begin{tabular}{|c|c|c|c|c|}
\hline Qenista Dialectus & Ano 5 & n.13 & Agosto - Dezembro 2018 & p. $228-244$ \\
\hline
\end{tabular}


presença de seus pares, os usuários não se sentem a vontade para relatar sobre os problemas sociais que os acometem.

Os/as profissionais relataram que durante seu exercício profissional no CRAS indígena, não houve a promoção de capacitações que contemplassem as especificidades indígenas e/ou qualificassem a realização de suas atividades. Logo, as práxis sociais desses profissionais ficam à mercê do seu desenvolvimento individual e comprometimento ético e político, como constatado no trecho abaixo:

Se eu participei de alguma capacitação durante o período de exercício na assistência social? - Sim, foram oferecidas algumas capacitações, mas com relação à especificidade da práxis social junto à população indígena não me recordo no momento. (PROFISSIONAL 5).

Mesmo diante dos constantes desafios para a execução das ações do PAIF os/as usuários/as conseguem identificar (mesmo sem tanta propriedade) benefícios e atividades promovidas pela equipe técnica, como no relato abaixo:

[...] já recebi benefício, assim, de curso, o Bolsa Família, recebi o kit de gestante, muito bom, ajudou muito viu [...] é a visita, o atendimento... Quando a gente chega lá, também, a gente é muito bem recebido, se a gente precisar eles vão até na nossa casa, ajuda a resolver os problemas. Quando a gente esta precisando, até conversar!, A gente chega no CRAS, desabafa lá, e pronto. O CRAS é muito importante. (NINA, USUÁRIA).

Embora a usuária avalie positivamente as ações e benefícios promovidos nas unidades de CRAS e o trabalho social desenvolvido, é presente em seu discurso a analogia à promoção de uma ajuda, distanciando-se da perspectiva de um direito social. Tal situação sinaliza os resquícios das protoformas da política de assistência social que se impregna no senso-comum e se intensifica nos tempos contemporâneos de desmontes e desqualificação dos direitos sociais.

\section{CONSIDERAÇÕES FINAIS}

Não temos a pretensão de esgotar aqui a discussão sobre a promoção equitativa da assistência social aos povos indígenas. Objetivamos, porém, lançar pistas para a compreensão dessa realidade.

A formação da sociedade brasileira impulsionou situações de subalternidade étnica e expropriação dos povos indígenas, que sob a égide de estereótipos sociais do "ser

\begin{tabular}{|l|l|l|l|l|}
\hline Gevista 2 ilalectus & Ano 5 & n.13 & Agosto - Dezembro 2018 & p. 228 - 244 \\
\hline
\end{tabular}


índio", a sociedade envolvente e o Estado construíram/constroem critérios de indianidade que os reportam a imagens congeladas dos/as indígenas do Brasil de 1500.

Os/as índios/as do Nordeste brasileiro passaram por um intenso processo de etnogênese. Por isso, são veementemente questionados por não se assemelharem como os/as indígenas isolados/as do Norte brasileiro, ou mesmo como no Brasil, em 1500.

No processo de operacionalização das políticas sociais públicas é crucial estar atento para os movimentos da realidade, identificando quais as nuanças do território e das famílias que lá habitam e desfrutam coletivamente do espaço. A política de assistência social vem sendo materializada por meio dos trabalhos sociais com famílias, mas, falta uma compreensão diferenciada por parte do poder público para a garantia de melhores condições de trabalho e capacitações continuadas, que, quando em territórios indígenas, acaba por imprimir lacunas na promoção equitativa desta política.

A garantia da equipe mínima do PAIF, por si só, não conseguirá suprir demandas cada vez mais crescentes no cotidiano profissional, mesmo porque essas requisições socialmente postas são adjacentes ao modo de produção capitalista. Porém, ressaltamos a necessidade de ampliá-la e inserir trabalhadores sociais com vínculos estatutários, com vistas a buscar a garantia da continuidade dos serviços.

A materialidade da assistência social depende, ainda, das elaborações conjunturais da sociedade que, na contemporaneidade, estão totalmente a mercê de orçamentos pífios e de direcionamentos políticos que mais aniquilam a promoção da assistência social que a garantem. Afinal, as marcas iniciais da assistência social têm, por vezes, desqualificado os ganhos normativos e operacionais que insistem em defini-la como uma "política" de benesses e ajudas.

A percepção territorial e a matricialidade sociofamiliar apresentam-se como importantes instrumentos de identificação do real e de projeção das práxis sociais que melhor se aproximam das respostas às demandas etnicamente diferenciadas. Dessa forma, é fundamental que os profissionais que atuam em CRAS que atendam o público indígena abstraiam qualquer tipo de estereótipo de indianidade distanciando-se de intervenções que representaram/representam uma atuação violadora e disciplinadora.

Afinal, ao imprimir em seu exercício profissional, posições baseadas no pensar da sociedade envolvente, desconsiderando a construção social e étnica do público demandatário, há possibilidades iminentes da incidência em atividades eurocentradas e neocolonialistas, correndo um sério risco de se travestirem em ações jesuíticas e colonizadoras de outrora.

\begin{tabular}{|l|l|l|l|l|}
\hline Govista Dialectus & Ano 5 & n.13 & Agosto - Dezembro 2018 & p. 228 - 244 \\
\hline
\end{tabular}


Assim sendo, é fundamental o diálogo constante com as lideranças da aldeia, visando imprimir em suas práxis, anseios reais do público demandatário, oportunizando um TSF equitativo.

\section{REFERÊNCIAS}

BARTOLOMÉ, Miguel Alberto. As etnogêneses: velhos atores e novos papéis no cenário cultural e político. Mana [online]. [S.1]: s.n. v. 12, n.1, p. 39-68, 2006.

BRASIL.Constituição (1988). Constituição da República Federativa do Brasil: promulgada em 5 de outubro de 1988. Brasília: Senado Federal, 2007 (Subsecretaria de Edições Técnicas).

BRASIL. Ministério do Desenvolvimento Social e Combate à Fome. Norma Operacional Básica de Recursos Humanos do Sistema Único de Assistência Social - NOB-RH/SUAS. Brasília: MDS 2009. Disponível em: <file:///C:/Users/Biellindo/Downloads/NOBRH_08.08.2011\%20(1).pdf>. Acesso em: 29 nov. 2016.

. Orientações técnicas sobre o PAIF: Trabalho social com famílias do serviço de proteção e atendimento integral à família. Brasília: MDS, 2012.

MDS, 2009.

Orientações técnicas: Centro de Referência de Assistência Social. Brasília:

. Política Nacional de Assistência Social. Brasília, MDS, 2004.

. Trabalho social com famílias indígenas: proteção social básica para uma oferta culturalmente adequada.[ Orientações técnicas]. Brasília: MDS, 2016.

CARNEIRO DA CUNHA, Manuela. Índios no Brasil: história, direitos e cidadania. São Paulo: Claro Enigma, 2012.

ESPINOSA, Monica. Ese indiscreto asunto de la violencia. Modernidad, colonialidad y genocidio en Colombia. In: CASTRO-GÓMEZ, Santiago; GROSFOGUEL, Ramon (Org.). El giro decolonial: reflexiones para una diversidad epistémica más allá del capitalismo global. Bogotá: Siglo del Hombre Editores; Universidad Central, Instituto de Estudios Sociales Contemporáneos e Pontificia Universidad Javeriana, Instituto Pensar, 2007. Disponível em: <http://www.ram-wan.net/restrepo/inv-antrop/espinoza.pdf >. Acesso em: 13 jan. 2017.

INSTITUTO SOCIOAMBIENTAL. Povos indígenas no Brasil: Quadro geral dos povos. Disponível em: <https://pib.socioambiental.org/pt/c/quadro-geral > . Acesso em: $20 \mathrm{de}$ dez. de 2017.

LUCIANO, G. S. O Índio Brasileiro: o que você precisa saber sobre os povos indígenas no Brasil de hoje. Brasília: LACED/Museu Nacional, 2006.

MARACANAÚ (Ceará). Secretaria de Assistência Social e Cidadania. Perfil das Famílias do Cadastro Único CRAS INDÍGENA. Maracanaú, CE: SASC, 2016.

\begin{tabular}{|l|l|l|l|l|}
\hline Q Povista Dialectus & Ano 5 & n.13 & Agosto - Dezembro 2018 & p. 228 - 244 \\
\hline
\end{tabular}


MARACANAÚ (Ceará). Secretaria de Assistência Social e Cidadania. Plano Municipal de Assistência Social de Maracanaú (2014-2017). Maracanaú, CE: SASC, 2014.

MARX, Karl. O capital: crítica da economia política - O processo de produção do capital. Tradução de Rubens Enderle. São Paulo: Boitempo, Livro, 1, 2013.

PINHEIRO, Francisco José. Mundos em confronto: povos nativos e europeus na disputa pelo território. In: SOUZA, Simone de; GONÇALVES, Adelaide. (Orgs.). Uma nova história do Ceará. 4. ed. Fortaleza: Edições Demócrito Rocha, 2007.

PINHEIRO, Joceny de Deus. Arte de contar, exercício de rememorar: história, memória e narrativa dos índios Pitaguary. 2002. 126f. Dissertação (Mestrado em sociologia) - Programa de pós-graduação em sociologia, Universidade Federal do Ceará, Fortaleza, 2002.

RAICHELIS, Raquel. Intervenção profissional do assistente social e as condições de trabalho no SUAS. Revista Serviço Social \& Sociedade, São Paulo: Cortez, n. 104, out/dez, 2010.

SILVA. Ivone Maria Ferreira. Questão social e serviço social no Brasil: fundamentos sociohistóricos. Cuiabá: EdUFMT, 2008.

\begin{tabular}{|l|l|l|l|l|}
\hline Qonista 2 ialectus & Ano 5 & n.13 & Agosto - Dezembro 2018 & p. 228 - 244 \\
\hline
\end{tabular}

